\title{
Intonation Metaphor
}

\author{
Canzhong Jiang \\ College of International Studies, Southwest University, Chongqing, China \\ Email: jczh273514@swu.edu.cn
}

Received 6 August 2014; revised 2 September 2014; accepted 10 September 2014

Copyright (C) 2014 by author and Scientific Research Publishing Inc.

This work is licensed under the Creative Commons Attribution International License (CC BY).

http://creativecommons.org/licenses/by/4.0/

(c) (i) Open Access

\begin{abstract}
As an important concept in Systemic Functional Grammar (SFG), grammatical metaphor can be categorized into ideational metaphor, interpersonal metaphor, arguably logical metaphor and textual metaphor on the basis of metafunctions. Ever since its initiation, grammatical metaphor, ideational metaphor in particular, has captured extensive attention from scholars throughout the world and various aspects including its categorization, motivation, realization, meaning and so on have been investigated. However, viewed from the perspective of language system, previous studies have been mainly focused on the stratum of lexicogrammar. Few have been directed at the phonological stratum which realizes lexicogrammar. It is suggested that phonological stratum also manifests such a metaphorical phenomenon. This paper will attempt to conduct an investigation on what we call intonation metaphor in this stratum in terms of its realization, motivation, semantics and functions. In addition, relationships among metaphors on the three linguistic strata will also be tentatively investigated.
\end{abstract}

\section{Keywords}

SFG, Grammatical Metaphor, Phonological Stratum, Intonation Metaphor

\section{Introduction}

In Systemic Functional Grammar (SFG), a language is regarded as a complex semiotic system comprising various levels or strata, including the stratum of semantics, the stratum of lexicogrammar, and the stratum of phonology.

In lexicogrammar stratum, Halliday proposes that vocabulary and grammar are not distinct strata. Instead, they are the two poles of one single continuum. Examined from the lexical pole, or "from below (from words to meaning)", traditional metaphor, or what is called lexical metaphor, can be conceived as meaning variation in the use of words (Taverniers, 2003), or rather variation between literal meaning and metaphorical meaning. A complementary perspective is "from the above", that is, starting with meaning, as is posited by Halliday. From this stance, meanings can be expressed or realized in various ways, which gives rise to Halliday's notion of 
grammatical metaphor. As is stated in An Introduction to Functional Grammar (Halliday, 1985: p. 320), "there is a strong grammatical element in rhetorical transference; and once we have recognized this we find that there is also such a thing as grammatical metaphor, where the variation is essentially in the grammatical forms although often entailing some lexical variation as well”.

In grammatical metaphor, congruent form and incongruent form which express or realize the same meaning are distinguished. A congruent form is deemed as the unmarked expression of a given meaning, conforming to the typical way of saying things or construing a situation or experience, which is the non-metaphorical usage. On the contrary, an incongruent form, i.e. the metaphorical usage, is the marked realization of a given meaning, conveying an atypical way of saying things or construing a situation or experience.

After its initiation, grammatical metaphor has been constantly enriched and developed with Halliday's continuous efforts in the elaboration of SFG and gradually becomes established as one of the most important concepts in SFG. According to Zhang and Dong (2014), the development of grammatical metaphor can be generally divided into three phases and three corresponding models have been provided by them, that is, functional model, stratified functional model and stratified systemic functional model. The period of functional model ranges from 1985 when Halliday published his first edition of An Introduction to Functional Grammar to 1994 when the second edition appeared. In functional model, grammatical metaphor is categorized into ideational metaphor and interpersonal metaphor under the guidance of ideational and interpersonal metafunctions, and investigated on the basis of functions of grammatical structural constituents. The second period is devoted to the stratified functional model ranging from 1995 to 2004 when the third edition comes out. Based on previous studies, Halliday and other scholars make a promotion of the functional model and the concept of stratification is given prominence in the second model. Motivations for grammatical metaphor have been probed from the perspective of language evolution and grammatical metaphor itself has been viewed as a metaphorical extension of the semantic system. The period of stratified systemic functional model, from 2004 till 2014 with the publication of the fourth edition, entrenches the systemic concept based on previous models. Logico-semantic relationship has been given priority to in the investigation of grammatical metaphor, which consolidates the belief in textual function of grammatical metaphor.

By mainly following Halliday's track, Zhang and Dong's clarification has offered us a thorough review of Halliday's contribution to grammatical metaphor. However, other scholars have also played a vital role in the development of grammatical metaphor. As has been presented, Halliday only explicitly distinguishes ideational metaphor and interpersonal metaphor within grammatical metaphor according to ideational and interpersonal metafunctions, with ideational metaphor being the focus of research. But according to Martin (1992), there should also be logical metaphor and textual metaphor since logical function is one aspect of ideational metafunction and textual metafunction is indispensable of the three metafunctions. Actually, He (2013), in his studies of textual metaphor, provides four types from the non-finite clausal perspective: elaborative non-finite clauses, extensive and enhancing non-finite clauses without relators, extensive and enhancing non-finite clauses with prepositions as relators, and enhancing non-finite clauses with prepositionalized non-finite verbs. But it is still controversial whether notions of logical metaphor and textual metaphor are necessary or not since some scholars claim that what logical metaphor deals with can also be interpreted by coherence and cohesion and what textual discuses has already been examined by ideational and interpersonal metaphor. In addition to its classification, motivations, realization, meaning and other aspects of grammatical metaphor have also been explored by scholars throughout the world, such as Ravelli (1988), Goatly (1993), Hu (1996, 2000), Yan (2000, 2003), Zhu \& Yan (2000), Fan (2001), Liu (2003, 2005), Zhu (2006), Zhang \& Zhao (2008), Lin \& Yang (2010), Cong (2011), Zhang \& Lei (2013). Cross-field studies in grammatical metaphor, such as studies from a cognitive linguistic view by Holme (2003), Ma \& Tao (2007) and Yang (2013), and a pragmatic view by Chen (2014), have also been conducted.

However, viewed from the perspective of language system, previous studies have been mainly focused on the stratum of lexicogrammar. The phonological stratum which realizes lexicogrammar has always been left in the shadow. Whether phonological stratum also manifests such a metaphorical phenomenon deserves further exploration. But Veltman (2003) has embarked on a heuristic research on what is called phonological metaphor, noting that intonation and prosody play a vital role. Zhang and Dong (2014) also mention that there is obviously intonation metaphor in phonological stratum, but they fail to provide any reason. This paper will attempt to conduct a detailed investigation on intonation metaphor in terms of its realization, meaning, motivation and other related aspects. 
This paper will be divided into five sections. In the first section, an introduction of grammatical metaphor including its initiation, development, classification and related researches is given. The second section will focus on variations of intonations at different rank, which paves a way for the discussion of intonation metaphor. The third and the fourth sections are the focus of this paper. A detailed study of intonation metaphor including its mechanisms of formation, realization, motivations, semantics and functions will be presented in the third section and the fourth section is devoted to a general investigation on relationships among metaphors on three language strata. Conclusions will be presented in the final section of the paper.

\section{Intonation Variations in Different Ranks}

Before a tentative discussion of intonation metaphor, a comprehensive characterization of intonation variation will be presented in this chapter. By intonation variation, it is meant that the same construction (with a limited sense, confined to the written form of phrase or group, clause, clause complex) can be realized by various intonations. In accordance with the spirit of SFG, experience with varying degree of sophistication can be categorized into element, figure and sequence. Element is the most basic semantic unit and figure is a configuration composed of elements. In turn, the conflation of figures gives birth to sequence. When realized in the stratum of lexicogrammar, element, figure and sequence will correspond to phrase or group, clause and clause complex respectively. All those ranks, including phrase or group, clause and clause complex, will finally be realized by corresponding phonological forms in which intonation plays an essential part. Consequently, intonation variation will be examined along the three ranks (For the convenience of discussion, units with tonic prominence will be marked in bold).

\subsection{Intonation Variation in Phrasal or Group Rank}

Phrases or groups, which realize element, the most basic semantic unit of experience, in turn, are realized by certain phonological forms accordingly. Intonation, one indispensable aspect of the phonological form, exerts great influence on the process of realization and can vary for different purposes. Phases including noun phase, verb phrase and preposition phrase, will be employed to illustrate how intonation operates in this rank.

(1) (a) a car;

(b) a car

(2) (a) walk towards school slowly;

(b) walk towards school slowly;

(c) walk towards school slowly;

(d) walk towards school slowly

(3) (a) in the box;

(b) in the box

In (1), two possible variations with different tonic prominence of a noun phrase with two constituents are listed as (a) and (b). Both (a) and (b) share the same lexical meaning. But realized by different phonological forms, or rather, different intonations, (a) and (b) are of considerable distinction in their pragmatic meaning. (1) (a) gives tonic prominence to "car" which profiles a thing and such a usage is usually taken as a generic interpretation of an indefinite noun phrase, in this case, the category of CAR, which can be conveyed by $A$ car is $a$ kind of vehicle. In (1) (b), the indefinite article "a” is phonologically salient, which brings it into a sharp contrast with "the car" or "two cars". (2) shows how a verb phrase with the same lexical meaning can express various pragmatic meanings through intonation variations. Only four possible variations are presented here and each of them profiles a different aspect of the "path image schema" with (a) profiling motion itself, (b), path, (c), goal and (d), manner. (3) illustrates the operation of intonation within the same preposition phrase with (3) (a) phonologically foregrounding the landmark in this phrase and (3) (b), the relationship per se.

Simple though the experience element is, it embodies complex variations when ultimately realized in the stratum of phonology and such variations reflect different ways of construing the world.

\subsection{Intonation Variation in Clausal Rank}

As more complicated experience, figure, consisting of elements, is also susceptible to intonation when finally 
expressed in phonological stratum.

(4) (a) The duke gave my aunt a tea pot.

(b) The duke gave my aunt a tea pot.

(c) The duke gave my aunt a tea pot.

(d) The duke gave my aunt a tea pot.

(e) The duke gave my aunt a tea pot. (falling tone)

(f) The duke gave my aunt a tea pot? (rising tone)

As is shown in (4), the same propositional meaning can be expressed in different phonological forms, with quite different tonic prominences or tone types. Accordingly, such differences usually give rise to a slight change of meaning, or an addition of pragmatic meanings. In detail, (4) (a) focuses on the agent of the process, "the duke” which answers the question "Who gave my aunt a tea pot?" In (4) (b), "gave” is salient, which answers the question "What did the duke do to the tea top?" (4) (c) corresponds to "Whom did the duke gave a tea pot to?”, making the recipient salient. (4) (d) echoes to "What the duke gave to my aunt?”, giving the patient a salient position. The phonological difference between (4) (e) and (4) (f) lies in their tone type. In (e) a falling tone is employed while in (f) a rising tone.

Figure is realized by clause in the lexicogrammar stratum and clauses are endowed with three metafunctions: ideational function, interpersonal function and textual function. Intonation is closely related to information structure and mood, and presumably textual function of a clause. In this sense, intonation variations convey various ways of construing a situation or experience.

\subsection{Intonation Variation in Clause Complex Rank}

Sequence representing the most sophisticated experience, unexceptionally, also falls within the influence of intonation when finally expressed in phonological stratum.

(5) (a) I do not trust him because he is dishonest.

(b) I do not trust him because he is dishonest.

Two possible phonological realizations with distinct intonation of the same complex proposition are provided here as example (5). In (a), "because" is prominent phonologically and conveys an interpretation that why he is not trusted. However, when "do not” is stressed, it seems that why he is not trusted does not lie in, or at least not exclusively lie in, his dishonesty.

Via such a simple example, a glimpse of how complicated experience sequence is construed in various ways through intonation which indirect realizes it in the phonological stratum, can be caught.

\section{Intonation Metaphor}

Intonation variations in different ranks indicate that different representations of human experience of the world can be achieved through their cognitive ability which is the basis for grammatical metaphor. Therefore, a grammatical metaphorical approach to intonation variations will be adopted here and those intonation variations, following the tenet of grammatical metaphor, will be analyzed into congruent form, or unmarked way of saying and incongruent form, or the marked way of saying. The tension between a concept or experience and its ultimate realization with varying intonations in the phonological stratum gives rise to what is called intonation metaphor.

\subsection{Congruence: Congruent and Metaphorical Intonation}

Congruence is one of the underlying concepts in grammatical metaphor, but it is also one of the most difficult concepts to clarify. Even now, no consensus in what is congruence has been reached among scholars.

According to Halliday (1998: p. 207), congruence means "that pattern of relationships between the semantics and the grammar in which the two strata initially co-evolved”. It can be sub-divided into congruence in rank and congruence in status. The former is reflected by the correspondence between semantic functions of sequence, figure and element and their respective realizations in lexicogrammar as clause complex, clause and phrase or group. The latter refers to the corresponding relationship that sematic functions of entity, process, quality, cir- 
cumstance and relator are respectively realized by noun, verb, adjective, preposition and conjunction. Therefore, forms conforming to such a correspondence are unmarked or typical ways of saying. Otherwise, they are marked or atypical, thus, metaphorical. In addition, a congruent form, from which a metaphorical form is derived, precedes the metaphorical form and is thus more basic and frequently used.

However, how can intonation variations be characterized by congruence, or how does congruence operate on intonation variations? Based on previous studies on congruence, it is observed that three aspects stand out in the description of intonation variations, that is, cognitive tendency, basicness and frequency of use. We think that congruent intonation patterns are more natural and acceptable in cognition, more basic and much earlier to occur and acquire, and more frequent and much wider in use.

Along the rank of clause, which corresponds to figure, it is argued that intonation is closely related to information structure and mood.

One information unit, usually co-extending with one clause, is structured by given and new information. On the basis of Halliday's analysis, the configuration of an information unit is typically or unmarkedly represented as given information followed by new information as is shown in Figure 1. Such a configuration reflects a natural cognitive tendency that new cognitive contents are recruited on the basis of those already cognized ones. From the perspective of ontogenesis, this configuration is also the first and most frequent one that children are exposed to.

Accordingly, this typical configuration of information structure is usually realized by a typical intonation pattern in which the new information is marked by tonic prominence (Figure 2). Such a typical intonation becomes more readily entrenched with high type frequency and is thus perceived as more basic, natural and acceptable.

Take (4) (a), (b), (c), (d) as an illustration (here repeated as (6)).

(6) (a) The duke gave my aunt a tea pot.

(b) The duke gave my aunt a tea pot.

(c) The duke gave my aunt a tea pot.

(d) The duke gave my aunt a tea pot.

The prototypical configuration of information structure and tonic prominence of this clause should be represented as Figure 3. In this sense, the congruent intonation pattern should be the one with "a tea pot” being phonologically prominent, which is realized by (d).

Other intonation patterns, as is displayed in Figure 4, are all metaphorical forms since they are incongruent with the typical representation of this process.

Similarly, in (7) (the repetition of (4) (e) and (f) as (7) here), this message typically goes hand in hand with a falling tone. Only in rare cases, for example as an echo question, is the rising tone employed. In other words, (a) with a falling tone is more frequent and entrenched than (b) with a rising tone. Therefore, (a) is the congruent intonation pattern and (b) the metaphorical one.

(7) (e) The duke gave my aunt a tea pot. (falling tone)

(f) The duke gave my aunt a tea pot? (rising tone)

In the lower rank of phrase or group, and the upper rank of clause complex, a similar motif in the delineation of intonation variations can be followed. Thus, a redundant representation will not be provided here.

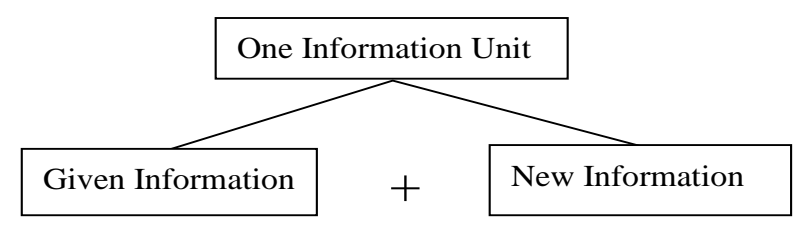

Figure 1. The typical configuration of one information unit.

\begin{tabular}{|l|l|c|}
\hline Information Structure & Given & New \\
\hline Tonic Prominence & Non-prominent $\longrightarrow$ Prominent \\
\hline
\end{tabular}

Figure 2. Intonation indication of information structure. 


\begin{tabular}{|l|l|c|}
\hline & \multicolumn{2}{|c|}{ The duke gave my aunt a tea pot. } \\
\hline Information Structure & Given & New \\
\hline Tonic Prominence & Non-prominent $\longrightarrow$ Prominent \\
\hline
\end{tabular}

Figure 3. Information structure and Tonic prominence of (d).

\begin{tabular}{|c|c|c|c|}
\hline (a) & \multicolumn{3}{|c|}{ gave my aunt a tea pot. } \\
\hline Information Structure & New & \multicolumn{2}{|c|}{\begin{tabular}{|c|} 
Given \\
\end{tabular}} \\
\hline Tonic Prominence & \multicolumn{3}{|c|}{ Prominent $\longleftarrow$ Non-prominent } \\
\hline (b) & \multicolumn{3}{|c|}{ The duke gave my aunt a tea $\mathrm{p}$} \\
\hline Information Structure & Given & \begin{tabular}{l|l} 
New & \\
\end{tabular} & Given \\
\hline Tonic Prominence & \multicolumn{3}{|c|}{ Non-prom. $\rightarrow$ Prom. $\longleftarrow$ Non-prom. } \\
\hline$(\mathrm{c})$ & \multicolumn{3}{|c|}{ The duke gave my aunt a tea pot. } \\
\hline Information Structure & Given & \begin{tabular}{l|l|} 
& New \\
\end{tabular} & \begin{tabular}{|c|c|}
$v$ & Given \\
\end{tabular} \\
\hline Tonic Prominence & \multicolumn{3}{|c|}{ Non-prominent $\longrightarrow$ Prominent $\longleftarrow$ Non-prominent } \\
\hline
\end{tabular}

Figure 4. Information structure and tonic prominence of (a), (b), (c).

\subsection{Motivations for Intonation Metaphor}

Intonation variations, no matter congruent intonation pattern or metaphorical ones, are all indirect phonological realizations of the same semantic function and it is the tension between semantic functions and their indirect realizations in the phonological stratum that leads to intonation metaphor. Intonation metaphor is well-motivated in the following ways.

Intonation metaphor can be seen as an alternative, possibly an economic way of grammatical variations. For instance, in the message, The duke gave my aunt a tea pot, conventionally, new information following given information, falls at the end of the clause. In accordance with such a convention, in cases where other parts are new information, a grammatical change or transformation, in Chomskyan fashion, of the clause will be involved. In this case, if "the duke", "my aunt", or "gave" are given the status as new information, the syntactic forms will accordingly altered as, A tea pot was given to my aunt by the duke, The duke gave a tea pot to my aunt, and What the duke did to the tea pot was to give it away. Instead of altering the syntactic form, intonation metaphor can gain the same effect by simply imposing tonic prominence on the new information regardless of its position in the clause.

The reason why intonation metaphor is possibly more economic than grammatical has something to do with iconicity. According to Langacker (2008), the processing of a clause arranged in an iconic order requires less time than one that is not. In this sense, language processing is, to a large extent, related to linear arrangement. For example, The book is on the desk in the study is an iconic arrangement since desk is the primary reference point against which the book is located while the study is the secondary reference point for the location of the desk and "the study" is, typically, the new information. When "the desk" is new information, the clause will be syntactically shifted into The book is in the study on the desk, which is not an iconic order of arrangement, thus, cognitively more demanding than the previous one. However, intonation metaphor achieves the goal by simply giving tonic prominence to the target without change the linear order. Therefore, it is assumed intonation metaphor is possibly more economic.

Intonation metaphor is also one of the various ways by which cognitive construes can be represented. One and the same experience can be construed in different ways in different contexts and by different conceptualizers, which can be conveyed in different strata of language. When realized in the stratum of lexicogrammar, those construes will result in grammatical metaphor and similarly intonation metaphor can be brought out when realized in phonological stratum. From a grammatical metaphorical point of view, Tom hit the ball is a sequential scanning while Tom gave a hit on the ball is a summary scanning of the same event. In a similar way, examined from the stance of intonation metaphor, Tom hit the ball is a construe focusing on the patient while Tom hit the ball is one that emphasizes the agent. Therefore, intonation metaphor, similar to grammatical metaphor, indicates certain ways of construing from phonological stratum. 


\subsection{Semantics and Functions of Intonation Metaphor}

Examined from below or their form, with the same written form, metaphorical and congruent patterns of intonation can only be distinguished from each other by their difference in phonological stratum. Viewed from above or their meaning, metaphorical and congruent patterns of intonation share the same linguistic meaning but they differ slightly in their pragmatic meaning. Phonological forms of intonation metaphor have been discussed in previous sections. This part will be devoted to its semantics and its functions.

In grammatical metaphorical studies, perhaps because a same linguistic meaning is usually realized by different grammatical forms, synonymy between congruent and metaphorical forms has been the focus though the importance of their differences in meaning has been realized. However, as for researches on intonation metaphor, it is suggested that, though synonymy is also an important notion, there is no point in emphasizing the synonymy between the congruent and metaphorical intonation patterns since they share the same grammatical forms and underlying linguistic meaning. Therefore, directions should be fixed on their semantic differences or pragmatic meanings in different contexts. Obviously, metaphorical intonation patterns are characterized by their own semantic or pragmatic maximal relevance in particular situations.

Functions of intonation metaphor can be characterized in terms of three lines of metafunctions. Firstly, intonation metaphor indirectly indicates particular construe of certain experience and is closely related to information structure in the clausal rank, which reflects its ideation function. In addition, it is correlated to mood which can be interpreted as its interpersonal function. Finally, coherence and cohesion can also be established through intonation metaphor by marking relevant new information with tonic prominence. In this sense, intonation metaphor is an alternative way of realizing textual function.

\subsection{Summary}

In this section, it has been argued that the phonological stratum also exhibits a similar metaphorical phenomenon as the stratum of lexicogrammar does and intonation metaphor may be one aspect of such a metaphorical phenomenon. Mechanisms for the formation of intonation metaphor, its realizations, motivations semantics and functions have been discussed in this section. Intonation metaphor is believed to be aroused by the tension between experience of the world or semantic function in language and its realization in phonology, and is syntactically and cognitively motivated. And investigations on intonation metaphor should be directed at semantic differences, instead of synonymy, between congruent form and metaphorical form. As for its functions, intonation metaphor is endowed with ideation function, interpersonal function and textual function.

\section{Relationships among Metaphors on Three Strata}

This section will be directed at what is meant by metaphors on the three strata of language and how they are correlated with each other.

\subsection{Metaphors on Three Strata}

As has been pointed out, language is seen as a semiotic system with three strata, that is, semantic stratum, lexicogrammar stratum and phonological stratum. As far as we are concerned, metaphors occur on each stratum.

Firstly, on semantic stratum, the way we think or the way we conceive and conceptualize the world around us is metaphorical. From a cognitive perspective, it is acknowledged that we usually resort to previous experience or already cognized concepts when we interact with the world. In other words, we usually interpret one conceptual domain in terms of another conceptual domain, which is what has been called conceptual metaphor. Conceptual metaphor operating at a conceptual level can also be said to function at the semantic level since conceptual structure is regarded as semantic structure which is one of the guiding principles of cognitive semantics. In this sense, we maintain that metaphors exist in semantic stratum and they are conceptual metaphors in cognitive linguistic sense.

Secondly, there are lexical metaphor and grammatical metaphor on the stratum of lexicogrammar, with lexical metaphor standing on the vocabulary pole and grammatical metaphor on the grammatical pole along the lexicogrammatical continuum. Grammatical metaphor includes ideational metaphor, interpersonal metaphor, and perhaps textual and logical metaphor, as has been introduced in the introduction part. Lexical metaphor is the tradi- 
tional notion of metaphor, or is the instantiation of conceptual metaphor in lexicogrammar.

Thirdly, intonation metaphor can be seen as a metaphorical reflection on phonological stratum.

\subsection{Relationships among Metaphors in Three Strata}

All of the three strata of language embody metaphorical properties and they interact with each other in the process of the realization of different linguistic functions.

From below, or from word to meaning or language to concept, lexical metaphor expresses various meanings through one lexical item, or conveys various concepts with one linguistic unit. This is an asymmetrical many-to-one mapping from concept to linguistic unit. From the above, or from meaning to word or concept to language, two subtypes can be distinguished. First, from concept to lexicogrammar, grammatical metaphor realizes one underlying lexical meaning through various grammatical structures, and this is an asymmetrical mapping from one concept to many linguistic structures. Second, from concept, indirectly, to phonology, intonation metaphor also indicates a many-to-one mapping from concept to linguistic form. It should be clear that linguistic forms of a linguistic unit include its grammatical form and phonological form andthat grammatical form alone cannot determine the entire meaning of a linguistic unit and phonological form also plays an important part, especially in spoken texts. In summary, such interrelationships can be represented in Figure 5.

\section{Conclusions}

Language as a unified system, has exhibited three levels of metaphor along its three strata, semantic stratum, lexicogrammar stratum and phonological stratum. Metaphor on the stratum of semantics has been the focus of conceptual metaphor in cognitive linguistics and lexical metaphor and grammatical metaphor have been devoted to the exposition of metaphor on lexicogrammar stratum. This paper is directed at metaphors on the stratum of phonology, intonation metaphor.

In conclusion, syntactically and cognitively motivated, intonation metaphor emerges from the tension between experience of the world or semantic function in language and its realization in phonology. Though realizing the same grammatical form and conveying the same linguistic meaning, metaphorical intonation pattern and congruent intonation pattern are different in their pragmatic meanings which should be the focus of intonation metaphorical investigation. As language provides us with ways of construing the world, interacting with others and constructing texts or discourses and lexicogrammar are dedicated to those functions, we maintain that intonation on phonological stratum also serves those functions, i.e. ideational function, interpersonal function and textual function, because it is also an indispensible part of language.

In addition, metaphors along the three linguistic strata are not in isolation. Indeed, they are externally and/or internally linked. From below, we have lexical metaphor reflecting a mapping from many concepts to one linguistic unit, while from above, we have grammatical metaphor and intonation metaphor indicating a mapping from

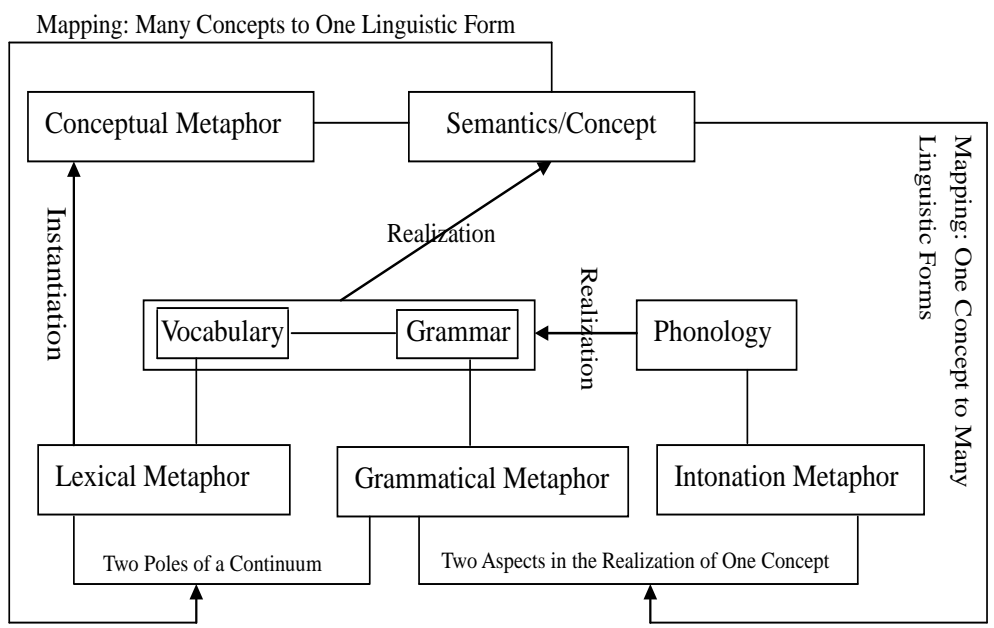

Figure 5. Relationships among Metaphors in Three Language Strata. 
one concept to various linguistic forms. Lexical metaphor instantiates conceptual metaphor and together with grammatical metaphor, they represents two pole along the continuum of lexicogrammar. Grammatical metaphor and intonation metaphor are two interrelated aspects in the realization of one concept or meaning.

\section{References}

Chen, X. R. (2014), A Pragma-Cognitive Account of Grammatical Metaphor. Journal of Foreign Languages, 2, 33-41.

Cong, Y. X. (2011). On the restraint and expansion of ideational grammatical metaphor. Journal of Foreign Languages, 5 , 46-53.

Fan, W. F (2001). Yufayinyulilunyanjiu (Theoretical Studies of Grammatical Metaphor). Beijing: Foreign Language Teaching and Research Press.

Goatly, A. (1993). Species of Metaphor in Written and Spoken Varieties. In M. Ghadessy (Ed.), Register Analysis Theory and Practice (pp. 110-148). London: Pinter.

Halliday, M. A. K. (1985). An Introduction to Functional Grammar (1st ed.). London: Edward Arnold.

Halliday, M. A. K. (1994). An Introduction to Functional Grammar (2nd ed.). London: Edward Arnold.

Halliday, M. A. K. (1998). Things and Relations: Regrammaticizing Experience as Technical Knowledge. In J. Martin \& R. Veel (Eds.), Reading Science: Critical and Functional Perspectives on Discourses of Science (pp. 185-235). London: Routledge.

Halliday, M. A. K., \& Matthiessen, C. (2004). An Introduction to Functional Grammar (3rd ed.). London: Edward Arnold.

Halliday, M. A. K., \& Matthiessen, C. (2014). Halliday’s Introduction to Functional Grammar (4th ed.). Oxon: Routledge.

He, Q.S. (2013). Textual metaphor from the non-finite clausal perspective. Open Journal of Modern Linguistics, 4, 308-313.

Holme, R. (2003). Grammatical Metaphor as a Cognitive Construct. In A. M. Simon-Vandenbergen, M. Taverniers, \& L. J. Ravelli (Eds.), Grammatical Metaphor: Views from Systemic Functional Linguistics (pp. 391-415). Amsterdam: John Benjamins. http://dx.doi.org/10.1075/cilt.236.21hol

Hu, Z. L. (1996). Grammatical Metaphor. Foreign Language Teaching and Research, 4, 1-7.

Hu, Z. L. (2000). A Review of Halliday’s Grammatical Metaphor. Foreign Language Teaching and Research, 2, 89-94.

Langacker, R. W. (2008). Cognitive Grammar: A Basic Introduction. Oxford: Oxford University Press. http://dx.doi.org/10.1093/acprof:oso/9780195331967.001.0001

Lin, Z. J., \& Yang, Z. (2010). A Study of Semantic Relations and Rank-Shift Directions in Grammatical Metaphor. Foreign Language Teaching and Research, 6, 403-410.

Liu, C. Y. (2003). The Stylistic Value of Grammatical Metaphor. Modern Foreign Language, 2, 120-127.

Liu, C. Y. (2005). Ideational and Interpersonal Metaphors: Opposite Rank-Shifts. Foreign Language Teaching and Research, 4, 289-293.

Ma, Y. L., \& Tao, M. Z. (2007). Grammatical Metaphor, Construction, Analogical Mapping. Foreign Language Education, 1, 40-44.

Martin, J. (1992). English Text: System and Structure. Amsterdam: John Benjamins. http://dx.doi.org/10.1075/z.59

Ravelli, L. (1988). Grammatical Metaphor: An Initial Analysis. In E. Steiner, \& R. Velman (Eds.), Pragmatics, Discourse and Text: Some Systemically-Inspired Approaches (pp. 133-147). London: Pinter.

Taverniers, M. (2003). Grammatical Metaphor in SFL: A Historiography of the Introduction and Initial Study of the Term. In A. M. Simon-Vandenbergen, M. Taverniers, \& L. J. Ravelli (Eds.), Grammatical Metaphor: Views from Systemic Functional Linguistics (pp. 5-33). Amsterdam: John Benjamins. http://dx.doi.org/10.1075/cilt.236.02tav

Veltman, R. (2003). Phonological Metaphor. In A. M. Simon-Vandenbergen, M. Taverniers, \& L. J. Ravelli (Eds.), Grammatical Metaphor: Views from Systemic Functional Linguistics (pp. 5-33). Amsterdam: John Benjamins. http://dx.doi.org/10.1075/cilt.236.17vel

Yan, S. Q. (2000). Metaphor, Metaphorization and Demetaphorization. Suzhou: Soochow University Press.

Yan, S. Q. (2003). The Development of the Grammatical Metaphor Theory and Its Theoretical Implications. Journal of Foreign Languages, 3, 51-57.

Yang, B. (2013). Ideational Grammatical Metaphor: A Cognitive Perspective. Journal of Foreign Languages, 5, 27-35.

Zhang, D. L., \& Dong, J. (2014). On the Developmental Models of Grammatical Metaphor. Foreign Language Teaching and Research, 1, 32-44.

Zhang, D. L., \& Lei, Q. (2013). Studies on Grammatical Metaphors in China. Foreign Language Education, 3, 51-57.

Zhang, D. L., \& Zhao, J. (2008). On the Formal Similarity Principle in Ideational Grammatical Metaphor between Congruent 
and Metaphorical Forms. Journal of Foreign Languages, 6, 25-32.

Zhu, Y. S. (2006). On Nominalization, Verbalization and Grammatical Metaphor. Foreign Language Teaching and Research, 2, 83-90.

Zhu, Y. S., \& Yan, S. Q. (2000). Contributions and Limitations of Halliday’s Grammatical Metaphor Theory. Foreign Language Teaching and Research, 2, 95-102. 
Scientific Research Publishing (SCIRP) is one of the largest Open Access journal publishers. It is currently publishing more than 200 open access, online, peer-reviewed journals covering a wide range of academic disciplines. SCIRP serves the worldwide academic communities and contributes to the progress and application of science with its publication.

Other selected journals from SCIRP are listed as below. Submit your manuscript to us via either submit@scirp.org or Online Submission Portal.
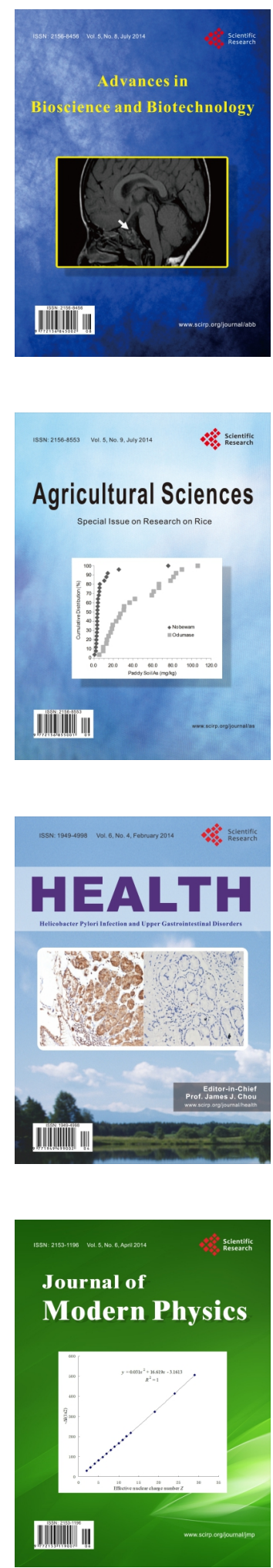
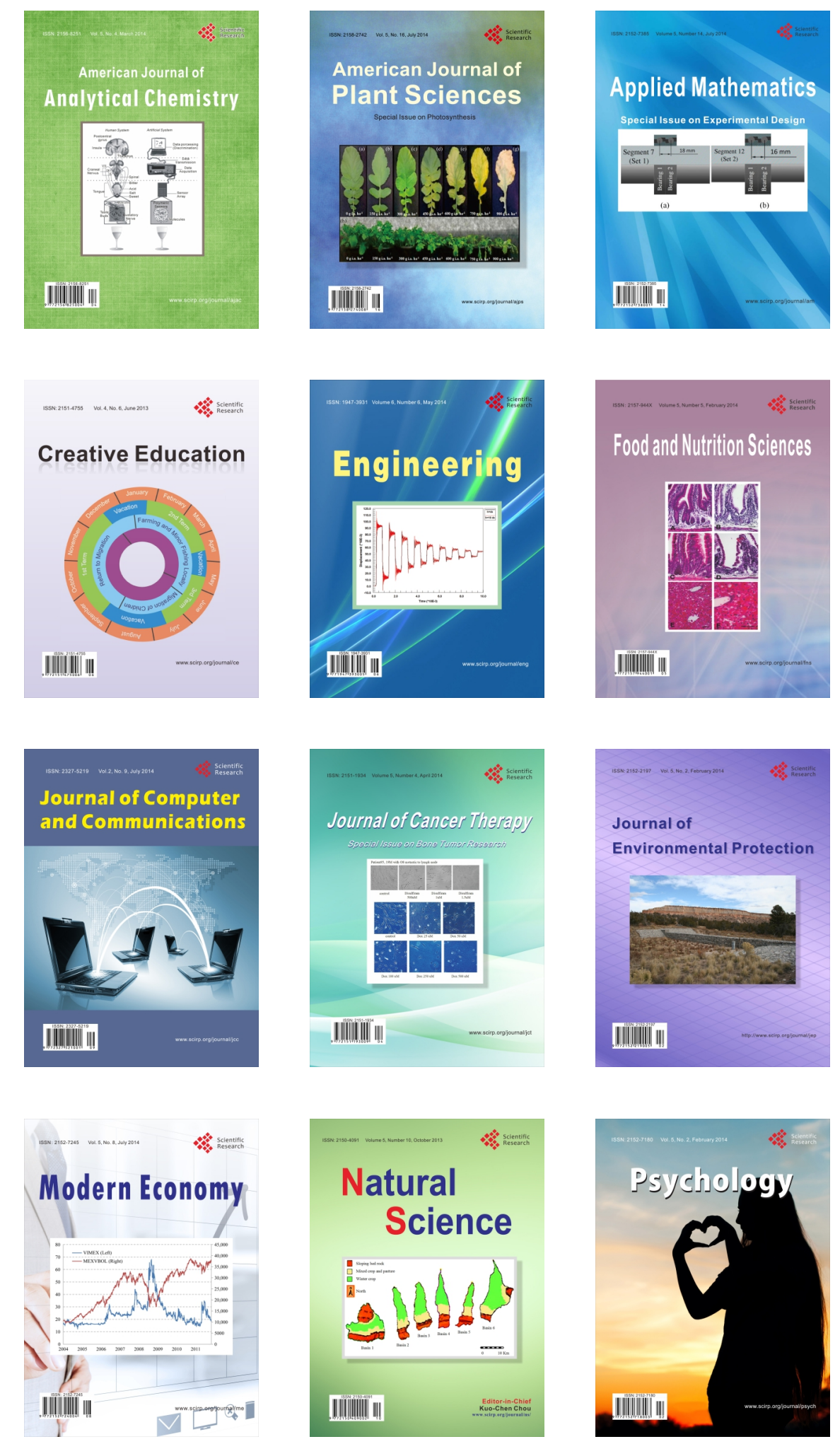